zou kunnen worden; daartoe zou men die stukken echter nader moeten onderzoeken en met andere opstellen in deze bunciss, als ook met reeds uitgegevene geschriften vergelijken.

Ten slotte zouden wij adviseren met den Heer de Sturler in onderhandeling te treden over den aankoop van de HSS. door hem gezonden, hetzij van alles of wel van enkele, waartoe in de eerste plaats de uittreksels uit het Rijks archief van 1659-1806, reeds in het vorige rapport vermeld, in overweging zouden kunnen komen. Het aangekochte zou dan in de bibliotheek van het Instituut geplaatst, later bij voorkomende gelegenheid voor historische onderzoekingen gebruikt kunnen worden."

De Vergadering vereenigt zich eenparig met dit adres en machtigt den Secretaris dienovereenkomstig te handelen.

Met het oog op de in het gebouw van het Instituut heerschende besmettelijke ziekte wordt goedgekeurd de vaststelling der plaats voor de volgende Bestuurs- en Algemeene Vergadering die den 18e en 25 Febr. zal moeten gehouden worden aan den Voorzitter en Secretaris over te laten.

Niets meer hierna aan de orde zijnde, wordt de Vergadering door den Voorzitter gesloten.

\title{
228STE BESTUURSVERGADERING,
} GEHOUDEN 18 FEBRUARI 1882.

Tegenwoordig de heeren van Rappard (Voorzitter), Kniphorst (Penningmeester), Quarles van Ufford, Robidé van der Aa, Niemann, Juynboll, Lammers van Toorenburg, van der Gon Netscher, Humme en Wijnmalen (Secretaris). Afwezig met kennisgeving, van Goltstein, Alting Mees en Meinsma.

De notulen van het verhandelde in de vorige Vergadering worden gelezen en goedgekeurd. 
Door den Secretaris-Bibliothecaris wordt verslag gedaan van de verschillende aanwinsten, waarmede de Bibliotheek wederom sedert de laatste bijeenkomst is verrijkt geworden, in verband waarmeê de ontvangst wordt bericht van eene missive van het Ministerie van Binnenlandsche Zaken, dd. 2 Febr. 1882 , no. 97 , Afd. K. en W., ten geleide van drie pakketten met boekwerken, van de Fransche Commissie voor internationale ruilingen uit Parijs voor het Instituut ontvangen.

Voor kennisgeving aangenomen.

Aangeteekend wordt, dat het medelid, Jhr. Mr. D. A. Junius van Hemert, te Utrecht, overleden is, terwijl de heer Mr. W. J. Essers eerlang weder naar Indië zal vertrekken, weswege beide namen worden afgevoerd van de lijst der Nederlandsche leden.

Onder herinnering aan de jongste uitgave van de 3 e of slot-aflevering van het $5 \mathrm{e}$ deel, 4e reeks, der Bijdragen, deelt de Secretaris mede dat de verschijning van eene nieuwe aflevering eenige vertraging zal ondervinden met 't oog op het oponthoud bij het drukken van den door wijlen Prof. Hoffmann bewerkten en door Mr. L. Serrurier uit te geven catalogus van Japansche boekwerken, in 1858 voor het rijk ingekocht, terwijl voorts eenige andere opstellen, voor die aflevering bestemd, nog niet zijn ontvangen.

De Voorzitter deelt vervolgens mede, dat is ingekomen:

10. eene missive van den Minister van Koloniën van den 26 Januari 1882, Lett. $A^{3}$, $n^{0}$. 14, houdende mededeeling dat bezwaarlijk getreden kan worden in het dezerzijds gedaan verzoek van 12 Jan. 1l., no. 1706, tot ondersteuning van een rekwest, onder gelijke dagteekening (no. 1705) aan den Gouverneur-Generaal van Nederlandsch-Indië gericht, strekkende om het Instituut alsnog op te nemen onder de instellingen, aan welke bij art. 32 van het Gouvernementsbesluit van 4 November 1881 (Ind. Stbl. no. 224) vrijdom van briefport is toegestaan.

Voor kennisgeving aangenomen.

20. eene missive van den heer A. L. de Sturler, te Leiden,

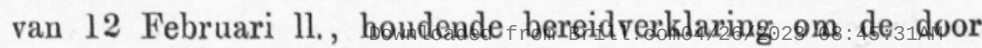


zijn vader nagelaten handschriften, meest betrekking hebbende op Palembang, aan het Institıut af te staan, doch, wat aangaat de aankoopsom door het Instituut te betalen, de bepaling der hoegrootheid daarvan aan de prudentie van het Bestuur te moeten overlaten.

$\mathrm{Na}$ eenige gedachtenwisseling wordt, den Penningmeester gehoord, besloten, den Secretaris te machtigen den heer de Sturler eene som van $f 10()$ aan te bieden.

$3^{0}$. eene missive van den heer M. A. van Rhede van der Kloot, te 's Gravenhage, van 17 Febr. jl., waarbij wordt aangeboden een door hem vervaardighd handschrift, getiteld: „De namen en wapens van de Gouverneurs-Generaal van Nederlandsch-Indië, met genealogische en historische aanteekeningen, 's Gravenhage, 1880," met verzoek voorts het werkje te beoordeelen, en meer speciaal na te gaan in hoever het voor het Koninklijk Instituut eenige waarde ter uitgave kan hebben.

Om bericht en raad in handen gesteld eener Commissie, bestaande uit de hh. Quarles van Ufford, Robidé van der Aa en Wijnmalen.

40. eene missive van hh. Commissarissen in Indië, dd. 6 Januari 1.l., Lett. B, ten geleile van de verantwoording van hun finantieel beheer over liet afgeloopen jaar 1881, eene opgave van de leden, die achterstallig zijn in het betalen hunner contributie, eene verbeterde Indische leảenlijst en eene opgave van de leden die in den loop van 1881 naar Nederland zijn vertrokken, dan wel door overlijden of bedanken hebben opgehouden lid van het Instituut te zijn.

Deze stukken worden in handen gesteld van den Penningmeester, ten einde daaromtrent in een volgende Vergadering advies uit te brengen.

Geven voorts Commissarissen hunne bevreemding te kennen dat zij geen antwoord hebben ontvangen op hunne laatste brieven en vinden zij ook daarin aanleiding hun ontslag te verzoeken, door den Secretaris worden, in aansluiting aan hetgeen door hem reeds vroeger was herinnerd, nadere mededeelingen gedaan, waaruit blijkt, dat de dezerzijds gezonden brieven, in antwoord op die der Commissarissen, niet of bij de verzending van hun schrijven nog niet in humne handen 
moeten gekomen zijn. Na eenige gedachtenwisseling wordt besloten den Secretaris te machtigen Commissarissen de noodige ophelderingen te geven, over een en ander het leedwezen van het Bestuur te betuigen en hun als zijn eenparig uitgesproken wensch te kennen te geven hunne aanvrage om ontslag alsnog te willen terugnemen.

Overeenkomstig de mededeeling van Commissarissen worden eindelijk tot leden van het Instituut benoemd de heeren Dr. W. van Lingen, predikant te Pekalongan, en L. F. Teyl Schuitenmaker, hoofdonderwijzer aan de kweekschool te Probolinggo, terwijl de tusschenkomst van Commissarissen zal worden ingeroepen tot het aanbieden van het lidmaatschap aan de heeren A. Haga, luitenant-kolonel, te Batavia, Dr. J. W. Hofmann, Directeur van het Krankzinnigengesticht te Buitenzorg, A. F. von de Wall en Dr. J. W. H. Gunning, letterkundigen te Batavia.

De Vergadering gaat vervolgens over tot de benoeming van nieuwe leden in Nederland. Eenparig werden daartoe aangewezen de heeren:

Mr. J. Heemskerk, Lid van den Raad van State;

Jhr. E. T. M. van Alphen, Lid van den Raad van State;

D. Maarschalk, Oud-Inspecteur-Generaal der Staatsspoorwegen op Java;

Jhr. Mr. V. de Stuers, Referendaris Dep. Binn. Zaken, afd. K. en W.,

allen te 's Gravenhage;

Dr. C. A. E. Wichmann, Hoogleeraar te Utrecht;

Dr. A. A. W. Hubrecht en Dr. F. A. Jentink, Conservatoren bij 't Rijksmus. voor nat hist. te Leiden;

Dr. C. Snouck Hurgronje, Leeraar aan de instelling van onderwijs in de Ind. Taal-, land- en vlk. te Leiden;

J. F. L. Schneider, Privaat-docent te Delft;

Dr. H Behrens, Hoogleeraar aan de Pol. school te Delft;

J. F. F. Moet, Oud-hoofdingenieur op Java, thans te 's Gravenhage;

Jhr. C. J. Goldman, Gep. O. I. hoofdambt. te 's Gravenhage;

P. W. Jansen, Directeur der Deli-Maatschappij te Amsterdam;

S. J. Spanjaard, Directeur der Java-Rameh-Maatschappij te Amsterdam; 
D. Cordes en M. P. Pels, Presidenten van 't Comité voor de internat. koloniale tent. te Amsterdam;

C. J. M. Jongkindt Coninck, Directeur aan 's Rijks landbouwschool te Wageningen;

Mr. P. van Bemmelen, Oud-rechter bij de int. rechtbank in Egypte, thans te 's Gravenhage;

M. Th. H. Perelaer, Gen.-Majoor O.-I. leger, te 's Gravenhage;

B. R. F. van Vlijmen, kap. $5^{\mathrm{e}}$ reg. inf. te Nijmegen;

G. J. van Kooten, Kapt. artillerie te 's Gravenhage.

H. Verploegh, Off. reg. Gren. en Jagers te 's Gravenhage ;

Mr. F. G. A. Reitz, Off. v. Justitie op Java, thans 's Gravenhage;

Mr. L. A. de Fielliettaz Bourquet, advokaat H.-R. te 's Gravenhage ;

Mr. J. de Sturler, Advocaat te 's Gravenhage.

Tot buitenlandsch lid wordt benoemd den heer Giacomo Doria, Directeur van het Muzeo civico di storia naturale di Genova, terwijl, overeenkomstig het voorstel der heeren Quarles van Ufford, tot correspondeerend lid wordt verkozen de heer J. C. Nieurdenburg, Directeur van het Nederlandsche Zendelinggenootschap te Rotterdam.

Van een en ander zal mededeeling worden gedaan aan de Algemeene Vergadering, aan welke tevens het voorstel zal worden gedaan om aan den hoogleeraar P. J. Veth het eerelidmaatschap van het Instituut aan te bieden.

Met leedwezen verneemt de Vergadering de aanvrage des heeren mr. F. Alting Mees om ontslag als lid van het Bestuur, waardoor nevens de drie vacaturen, ontstaan door de periodieke aftreding van de bestuursleden van Rappard, Robidé van der Aa en Prof. Meinsma, in eene nieuwe vacature zal moeten worden voorzien.

Voor elk dier vacatures worden vervolgens drietallen opgemaakt, welke aan de Algemeene Vergadering zullen worden aangeboden.

Zij zijn :

$1^{\circ}$. voor de vacature-van Rappard de hh. H. J. Bool, F. G. van Bloemen Waanders en mr. J. G. Patijn.

$2^{\circ}$. voor de vacature-Meinsma de hh. Prof. dr. G. Schlegel en Prof. A. C. Vreede.

3o. voor de vacature-Robidé van der Aa de hh. Dr. T. C. 
L. Wijnmalen, mr. S. ('. J. W. van Musschenbroek en G. J. Buijskes.

4o. voor de vacature-Alting Mees de hh. A. W. G. Weitzel, P. G. Booms en Egter van Wissekerke.

Namens de Commissie, bestaande nit de hh. Quarles van Ufford en Humme, wordt bij monde van eerstgenoemde rapport uitgebracht over de haar in de vorige Vergadering aangeboden rekening en verantwoording van de Penningmeester over het dienstjaar 1881. Zij heeft haar in volkomen orde bevonden, waarom zij voorstelt haar vanwege het Bestuur als goedgekeurd te beschouwen onder dankzegging aan den Penningmeester voor zijn zorgvuldig beheer. Dienovereenkomstig wordt eenparig besloten, terwijl tevens wordt goedgekeurd de rekening alsnu in handen te stellen van twee gewone leden, ten einde daaromtrent der Algemeene Vergadering te dienen van bericht en raad. De Secretaris wordt gemachtigd daartoe de hh. Weitzel en van Bloemen Waanders uit te noodigen.

Door den Secretaris wordt ter tafel gebracht een door hem in de Algemeene Vergadering voor te dragen Verslag van den staat en de werkzaamheden van het Instituut van 1881. $\mathrm{Na}$ eenige wijzigingen wordt het goedgekeurd, waarna tevens voorlezing wordt gedaan van een mede door den Secretaris opgemaakt Verslag over den toestand van de aan zijne zorgen toevertrouwde bidliotheken van het Instituut en het Indisch genootschap, dat ingevolge de bepalingen van het Bibliotheekreglement zal worden gedrukt en aan de leden van beide instellingen rondgedeeld.

Voor de vervulling dezer dubbele taak wordt den Secretaris door den Voorzitter de dank der Vergadering aangeboden.

Niets meer hierna aan de orde zijnde, wordt de Vergadering door den Voorzitter gesloten. 